\title{
El oficio de la enseñanza de un idioma extranjero y la competencia social
}

Maurizia D'Antoni ${ }^{1}$

Para ser buen profesor es necesario estar preparados en varios aspectos de este oficio. Por ejemplo, es necesario adquirir la pericia, o la cualidad específica del profesor que se ha hecho experto mediante la práctica cotidiana de aquel (Carretero, 1987).

Así, los profesores de idiomas que enseñan su lengua en otro País, además de ese camino hacia la experiencia, tendrán que resolver también los conflictos cognitivos propios del acercamiento entre culturas.

Por competencia social entendemos la característica, que se adquiere, de ser competente en sociedad, y se mide según que tanto somos capaces de obtener los efectos que deseamos sobre los demás (Argyle, 1994).

1. Educadora y psicóloga italiana. Universidad Nacional de Costa Rica. E-mail: MAUDANTONI@HOTMAIL.COM 
Es muy deseable conocer otros idiomas en nuestro mundo globalizado: lo anterior es más evidente si se trata de a/prender los idiomas de los países políticamente y económicamente poderosos.

El conocimiento del inglés se ha hecho indispensable en cualquier parte del mundo: consumimos páginas internet, publicaciones, películas, canciones y videos. En Costa Rica no son pocos los anuncios económicos publicados en la prensa nacional, directamente en lengua inglesa, que ofrecen trabajo a los ciudadanos. Un ejemplo entre todos es el nuevo y discutido mercado de las apuestas telefónicas, que implican únicamente tener un dominio total del idioma inglés: ningún título de estudio o preparación previa.

El italiano es, hace algunos años, otro idioma 'exitoso'. Según datos de una investigación de la Universidad La Sapienza de Roma, citados por la $\mathrm{RAI}^{2}$, la demanda de conocimiento del italiano ha crecido en los últimos años en el mundo, hasta en un $30 \%$.

Es evidente, si observamos los acontecimientos ligados a la inmigración en Italia, que este país europeo, en los últimos diez años (o menos) se ha convertido en un destino apetecido por masas de personas empobrecidas en el mundo que se mueven para buscar mejores oportunidades de vida. Italia tiene una "historia frustrada" como país colonialista: su "conquista africana" fue breve, trágica y no creó los lazos culturales, políticos y los corredores de inmigración que tradicionalmente han vinculando mutuamente potencias europeas y países en proceso de desarrollo.

En la capital de Costa Rica crece el número de las escuelas que imparten o que incluyen la enseñanza de la lengua italiana.

2. Noticiero "Qui Roma", RAI INTERNATIONAL; 29 de diciembre del 2001. 
Las hipótesis que nos proponemos a continuación son el resultado de observaciones y de comentarios de los estudiantes a lo largo de doce años de enseñar el italiano a estudiantes en su mayoría costarricenses, provenientes de San José o áreas aledañas.

Es probable que el italiano se considere un idioma 'lindo' o 'fácil', que la representación que los costarricenses se han construido de Italia sea la de un lugar poco amenazante y la supuesta dulzura fonética del idioma se aplique al carácter social de las personas que lo hablan.

Existe otra hipótesis sobre el interés por un idioma cuyo conocimiento no asegura en Costa Rica oportunidades profesionales directas, y que responda al deseo de aplicar a una beca. Tenemos una renovada, si bien tímida, oferta de becas de estudio para Italia, así como el inicio de un incipiente movimiento migratorio desde el Valle Central costarricense a Italia, a la vez de que se nota la presencia de un constante, aunque reducido en número, movimiento turístico de Italia hacia Costa Rica.

Es necesario destacar también que los muchachos que asisten a clases de italiano son en su mayoría colegiales y universitarios: tienen edades que oscilan entre los quince y los veintiocho años de edad. Esos mismos jóvenes, por lo tanto, eran niños o adolescentes en la "época dorada" del Mundial de fútbol de 1990 en Italia, año en el que, por primera vez, el equipo costarricense alcanzó los octavos de final en un torneo mundial. 'Esa' Italia, acogedora y de buen auspicio, formaría parte de su imaginario infantil.

Cualquiera que sea la motivación que mueve los costarricenses al estudio del italiano, ella forma parte de una representación: en lo concreto el profesor que imparte las clases se encuentra ante una visión del idioma y del País que lo habla. Tiene por ende unas expectativas. Una entre todas, la citada esperanza que se trate de un idioma armonioso se vincula con la creencia que su aprendizaje resulte 'fácil'. 
A su vez, el profesor es en la mayoría de los casos, un extranjero que puede haber inmigrado a Costa Rica siendo un adulto, con su recorrido personal en el silencio de los políglotas y en el desacuerdo con la cultura que lo hospeda, como evoca Julia Kristeva (1988).

El docente habrá enfrentado su camino para la integración y los numerosos desafíos de tipo cognitivo que éste implica. Sólo que el resultado de tal proceso -que si se quiere, para usos del presente artículo, se puede diferenciar entre los embates del corazón y la perplejidad frente a lo nuevo- por razones profesionales, el docente lo lleva a su trabajo diario.

Interesa destacar la importancia de la competencia social del docente, que es un extranjero, y las implicaciones que su evolución en la adquisición de la competencia social en la nueva cultura pueda tener en el proceso de enseñanza-aprendizaje del idioma italiano.

\section{Las destrezas sociales}

Las destrezas sociales (social skills) son una parte del estudio de la competencia social (social competence) e involucran lo que se refiere a la conducta.

Las destrezas sociales son patterns (patrones) de conducta social que hacen de los individuos personas competentes en el intercambio social. Se define esa competencia como una capacidad del sujeto de influenciar a los demás, de producir los efectos deseados sobre los demás.

La investigación (Argyle, 1994) hace una diferencia entre destrezas sociales personales y profesionales. Las destrezas sociales personales ponen al individuo en la situación de poder alcanzar metas para beneficio personal, como por ejemplo "caerle bien a los demás". Las destrezas sociales de orden profesional le otorgan al individuo la capacidad 
de acrecentar sus capacidades de trabajo o de aprendizaje. Son éstas últimas las que importan más en el caso de los profesores de idioma extranjero.

En el ámbito de la competencia social y de las destrezas sociales, existen también vertientes que pueden complicar su puesta en acto: vertientes ligadas a la motricidad de la persona, a su saber, su comprensión y la ausencia de ansiedad con respecto a la tarea que debe de realizar ( $\mathrm{Ar}$ gyle, 1994).

\section{Utilización del concepto en ámbito laboral}

La evaluación de la competencia social del individuo se ha utilizado en el ámbito laboral: será evidentemente beneficioso analizar la competencia social de un extranjero trabajando en Costa Rica como profesor de su idioma. El conocimiento del tema facilitará su labor a la vez que será de utilidad para construir una propuesta de capacitación que incluya elementos de aprendizaje de competencia social y de destrezas sociales específicas.

El trabajador, de primera entrada, aun conociendo el español y teniendo su propia representación de Costa Rica, puede no estar al tanto de todo ese mundo de convenios tácitos y específicos que se crean entre profesor y alumno en cuanto a la conducta dentro el aula, a la disciplina, la directividad y otras, así como la respuesta del docente que los alumnos han llegado a considerar apropiada dentro del contexto del aula.

Los alumnos, al ver roto el pacto tácito que fueron acostumbrados a mantener con el o la docente pueden ver interferido el proceso de aprendizaje al interpretar la novedad, por ejemplo, en términos de descalificación de la competencia del docente, en un sentido que no involucra la sola competencia social sino también el ámbito profesional específico. 
El docente mismo, por su parte, puede interpretar de manera errónea peticiones al cambio que los alumnos implícitamente le hacen como, por ejemplo, hostilidad de parte de la clase.

La competencia social y profesional se aprende, pero en este caso se postula la oportunidad de no dejar su construcción, en el caso del docente de idioma extranjero y de nacionalidad extranjera en Costa Rica, al proceso espontáneo dentro de la construcción de la pericia del docente. Véase el caso de los profesores de inglés, cuya rotación en algunas instituciones de San José es extrema, debiendo suponerse que el abandono del puesto de trabajo tiene, entre otras explicaciones, la de una insuficiente capacitación.

La capacitación que comprendiera la problemática de la competencia social y de las destrezas sociales, en efecto, sería beneficiosa para el docente, sus alumnos y la institución que promueve el aprendizaje del idioma extranjero.

En el mérito de la competencia social laboral, el concepto ha sido utilizado en las investigaciones relativas a la medición objetiva de la eficacia del logro en el trabajo.

Existe una tradición de investigación acerca de la evaluación del mérito del desempeño profesional, por parte de los jefes o de los colegas, con la dificultad de que se midan los resultados del trabajador en ámbitos laborales homogéneos.

Las entrevistas de trabajo a menudo pretenden medir la competencia profesional: se prefiere sin embargo realizar una proyección sobre esa cualidad del aspirante al puesto investigando el desempeño profesional en anteriores ámbitos laborales, por representar la entrevista un momento inusitado con respecto a la situación laboral en sí (Argyle, 1994). 
El trabajo del profesor: sobre el modelo de las competencias sociales

Existen trabajos que más que otros implican la necesidad de un buen desempeño del profesional en el ámbito de las destrezas sociales. Es muy obvio el ejemplo de camareros y vendedores cuya capacidad en el campo aludido representa un enorme beneficio para la compañía que los contrata.

En cuanto a las relaciones con el extranjero, hay estudios que prueban cómo el profesional que se traslada al exterior, por ejemplo con los Cuerpos de Paz, tiene una probabilidad de fracaso profesional igual al 60\%. Argyle (1984) muestra cómo la probabilidad de fracaso es mayor aún si la migración se da de países occidentales a países del Oriente medio: en los años ochenta las poblaciones estudiadas volvían a su país de origen, en su mayoría, después de uno o dos años de desempeño profesional. Para la organización contratante lo anterior significa costos de capacitación, gastos para repatriar al personal, y todo tipo de ajustes e inconvenientes ligados a la rotación.

El docente es un profesional constantemente en contacto con los demás. Capacitar en las destrezas sociales necesarias para un buen desempeño profesional del docente puede representar una tarea de la inducción una vez que las instituciones contratantes tengan claro el papel de la competencia social en el desempeño profesional general.

Argyle (1994) menciona un estudio anterior sobre la competencia social. Allí propone un modelo teórico acerca de la competencia social, que compara con el modelo de las competencias motoras: por ejemplo manejar el carro. El chofer de un carro mueve la manivela: cuando el movimiento obtenido no es de su satisfacción, a los pocos segundos corrige la maniobra para obtener una más eficaz para sus fines. 
De igual manera, la persona socialmente competente debería poder:

- $\quad$ Tener algunos objetivos;
- proceder de manera inteligente;
- percibir los efectos de su acción;
poder corregir su manera de proceder.

Entre los procesos que se han tomado en consideración en el debate teórico están la asertividad, en cuanto capacidad de influenciar positivamente al otro; la comunicación, verbal y no verbal, la gratificación, reconocida en general como la capacidad, por ejemplo, del buen líder de darle atención a las necesidades de los demás.

\section{Competencia social y didáctica de las lenguas modernas}

Las discusión sobre la didáctica de las lenguas se ha ampliado recientemente, para incorporar los conocimientos acerca de bimodalidad y los nuevos conocimientos neurolingüísticos al proceso de enseñanza - aprendizaje. Hoy sabemos que el cerebro humano procesa las informaciones de manera compleja: diferentes partes del cerebro funcionan sincrónicamente (Danesi, 1998).

La investigación, paradójicamente le agrega complejidad al modelo que se tenía del funcionamiento neurolingüístico, pero descubre que existen autopistas cerebrales ya trazadas para el recorrido de un estímulo lingüístico y su procesamiento; y la didáctica de un idioma debería aprovechar tales caminos. La investigación en ámbito neurolingüistico ha contribuido a la construcción de una didáctica que tome en cuenta la actividad funcional del cerebro, proponiendo facilitar automatismos donde la vía para la localización cortical del idioma extranjero pasaba tradicionalmente 
por memorización de conceptos gramaticales: una vez memorizados los conceptos había que aplicarlos, luego de un proceso que implicaba llamar a la memoria y reflexionar.

Los profesores de idiomas extranjeros contamos con la riqueza de la teoría acerca de la competencia social y algunas referencias acerca de la importancia de los nuevos conocimientos neurolingüísticos en la didáctica de una lengua extranjera: vamos a intentar utilizarlos para dar una dirección a la didáctica del maestro de un idioma extranjero, en este caso el Italiano, en Costa Rica.

Es importante subrayar, por un lado, que el aprendizaje de un idioma extranjero es sustentado por mecanismos inconscientes, en parte estrictamente de comperencia neurolinguística, en parte involucran explicaciones que puede darnos la psicología social.

De los nuevos conocimientos sobre el cerebro se sirve ahora la moderna neurolingüística, que informa así las gramáticas y los métodos que están a disposición de los/las profesores/as.

Para nosotros es necesario que el docente comprenda la función de su trabajo y evite la tentación de pasar por la esquematización de la regla gramatical, y pueda comunicarle al alumno que el aprendizaje de una lengua extranjera ¡es fácil! Con eso entendemos que el funcionamiento de nuestro cerebro "naturalmente" nos lleva a adquirir informaciones, a clasificarlas y utilizarlas, de manera muy parecida a como lo hemos hecho para adquirir nuestro idioma materno, ${ }^{3}$ sin pasar por racionalizaciones o categorizaciones conscientes. El docente, haciendo tesoro de lo que sabe sobre el aprendizaje de un idioma extranjero podría jugar en su clase, sin insistir con el uso de la pizarra para tratar de

3. Se reconoce la importancia del tema de la cantidad de horas de clase y la regularidad de la asistencia del estudiante, sin embargo lo que interesa subrayar aquí es el enfoque novedoso con respecto a la didáctica tradicional. 
recoger conceptos en cuadros escritos. Al grupo de estudiantes, mudos, les tocaría atrapar el conocimiento, copiándolo en su cuaderno.

En la escuela de italiano, los alumnos tienden a poner al docente, que viene de otro ámbito socio cultural en un papel que el extranjero siente insólitamente vertical y proponen constantemente una esquema de aprendizaje marcado por el control externo. Consiste en preguntar insistentemente acerca de la evaluación, pedir que se evalúe a través de exámenes escritos, a la vez que están extremadamente nerviosos a la hora de realizarlos. Un ejemplo: en el mes de mayo del 2002 la Dirección Didáctica confeccionó una nueva evaluación en la que la nota es un juicio (muy bien, bien, suficiente, etc.) y no un número. En la mayoría de las clases el cambio es acogido desfavorablemente y algunos alumnos piden que se cambie el juicio por un número.

Con igual regularidad el/la estudiante pide que se realicen tablas en la pizarra que capturen por él o ella el conocimiento, que el alumno diligentemente copia. Una similar aptitud de captación aparece, acompañada por la ansiedad con la que se pide, o se busca, contraviniendo la metodología pactada, la palabra en el diccionario. Es evidente el alivio con el que el estudiante copia en su cuaderno la palabra nueva con la traducción a latere, sin darse siquiera cuenta que su exploración del diccionario ha significado para él o ella la exclusión, voluntaria, de tiempo de clase. Esa necesidad de interponer entre uno mismo estudiante y el idioma extranjero que se está aprendiendo, una pantalla de racionalización defensiva, dificulta el aprendizaje. La consideración anterior nos ayuda a pasar al concepto de mente, vista como modalidad de funcionamiento superior ligado también al ambiente, a circunstancias sociohistóricas en las cuales nos encontramos inmersos, y por las cuales somos determinados. El proceso de enseñanza y aprendizaje ha 
representado para el costarricense medio, se infiere de su conducta en las clases de italiano, un recorrido peligroso al cual ha logrado sobrevivir solamente empeñándose en estrategias defensivas que ahora aplica a la escuela que escogió para pasar su tiempo libre y en donde es un cliente merecedor de la atención que le debe el atestado mercado de los institutos de idiomas.

El docente de idiomas distraído puede caer en la trampa de identificarse con el maestro severo, en lugar de considerarse a sí mismo como el prestador de un servicio, un técnico preparado entre iguales que apela a la institución que representa para obtener una prestación profesional.

\section{Discusión}

Los estudiantes de Costa Rica llegan a las clases de italiano a menudo heridos en su autoestima. El uso del error del discípulo por parte del maestro es un tema que ha sido abordado y es más fácil interpretarlo como una herramienta de dominación que como un recurso para el aprendizaje; didáctica clásica hacia el aprendizaje por prueba y error.

Los estudiantes llegan a las clases de italiano con una historia de vida y de escuela donde han aprendido a leer el papel del estudiante y del profesor en una escala jerárquica y en un contexto socio cultural. El maestro induce al aprendizaje esgrimiendo su papel de superioridad.

Costa Rica es un país que fue colonizado de manera violenta en un pasado que parece remoto pero no lo es en el imaginario, en un inconsciente que, como se sabe, es atemporal. El recuerdo histórico de tal dominación se ha plasmado en la cultura mestiza que nació de la Conquista, desembocó en la Colonia y nos acompaña en la estratificación social de hoy. (Molina y Palmer, 1997). La tenencia de las tierras y de los cultivos se 'moderniza' en la forma: la presencia 
en los consejos de administración de las firmas importantes, de los medios de comunicación, en los puestos del gobierno abre muy poco a las clases 'burguesas'. El poder sigue heredándose en vasta medida y la fuerza de una clase que se abre campo por sus puros méritos y esfuerzos es todavía caso aislado.

Dentro de este marco grueso, es fácil para las personas, en su vida cotidiana seguir representándose las relaciones como las mismas relaciones de poder que se conocen.

Los que hablan español y los que no, los que son de aquí y los que han venido, los que mandan y los que son mandados, los que tienen la tierra y los que no la tienen, los hombres y las mujeres, los padres y los hijos..., los alumnos y los maestros.

Las dicotomías de nuestra 'cultura de guerra' (Galtung, 1996) no solo nacen aquí como triste simplificación de la contemporaneidad globalizada: se insertan en un mundo interior que las conoce bien, hace mucho: desde cuando fueron impuestas con la fuerza y cambiaron para siempre el rumbo de un desarrollo todavía posible entonces y hoy perdido para siempre.

Lo que sí es necesario poner en duda son las consecuencias de tal representación en las relaciones entre grupos y personas. La idea de sí mismos como de un pueblo 'de clase media', igualitario, de posibilidades y equivalencias sufre ante las modernas dicotomías, las frustraciones reales de los sueños y lleva a las personas a recordar y retomar fácilmente los sabidos modelos autoritarios.

La propuesta se vincula con el hecho de que conocer el funcionamiento neurolingüístico del cerebro nos ayuda a entender que aprender un idioma extranjero puede, debe ser fácil, en el sentido de que puede ser propuesto como una aventura que no pone en riesgo la autoestima de la persona, la continua posibilidad de un éxito o de un fracaso donde está en juego la imagen que se tenga de sí. 
Ayudados por la teoría de la competencia social los profesores nos acercamos a la conciencia crítica que un papel autoritario, una cultura de aprender por obligación y castigo, es menos provechosa que la alianza con la mente activa de los alumnos, su posibilidad de cambio a través de la reflexión y del contacto con lo nuevo.

\section{Bibliografía}

1. Argyle, Michael. 1984. "Some new developments in social skills training". En: Bulletin of the British Psychological Society. 37, pags. 405-410.

2. Id. 1994. "Le competenze sociali". Pags 105-142. En: Moscovici (curad.), cit.

3. Carretero, Mario (comp.). 1987 Procesos de enseñanza y aprendizaje. Trad. españ. Aique. Buenos Aires.

4. Danesi, Marcel. 1998. Il cervello in aula! Neurolinguistica e didattica delle lingue. Edizioni Guerrra. Perugia.

4. Galtung, Johan. 1996. Peace by Peaceful Means. PRIO/Sage, OsloLondres.

5. McLaren, Peter (comp.). 1997. Pedagogía, identidad y poder. Trad. esp. Homo sapiens ediciones. Rosario.

6. Molina, 1; Palmer, S. 1997. Breve Historia de Costa Rica. Editorial Universidad de Costa Rica, San José.

7. Moscovici, Serge (comp). 1994/1997. La relazione con l'altro. Trad. ital. Raffello Cortina Editore. Milano.

8. Valiña, María Dolores y Martín, Montserrat. 1997. Psicología cognitiva. Perspectiva histórica, métodos y metapostulados. Pirámide, Madrid. 